\title{
Uplift capacity of rapidly loaded strip anchors in uniform strength clay
}

\author{
C. P. THORNE*, C. X. WANG† and J. P. CARTER*
}

The behaviour of horizontal strip anchors buried in clay is examined in this paper. $A$ brief critique of the various approaches suggested for the design of these anchors is presented, with emphasis placed on estimation of the ultimate load that these anchors can withstand when loaded rapidly in uplift under undrained conditions. Possible mechanisms of failure are reviewed, including shear and tensile failure within the soil and the development of suction within the pore fluid, and the results of finite element predictions are compared with experimental data for ultimate loads. The analyses reveal that the behaviour of strip anchors in uplift is a function of the following non-dimensional parameters: $H / B, \gamma H / c$ and $u_{\mathrm{c}} / c$, where $H$ is the depth of embedment of the anchor, $B$ is the width of the strip anchor, $\gamma$ is the unit weight of the soil, $c$ is its undrained shear strength, and $u_{c}$ is the magnitude of the maximum tensile stress that can be sustained by the pore water in the soil. It is demonstrated that the ultimate uplift capacity is dependent on the availability of water at the surface of the soil and within the soil beneath the strip anchor. The analyses also show that shallow anchors in relatively strong soil tend to fail by the development of tensile failure in the soil above the anchor. The ultimate capacity of these shallow anchors is a function of the undrained shear strength of the soil, its self-weight and the tensile capacity of the pore fluid. By contrast, the failure mechanism for deeply buried anchors where the initial vertical total stress at the plate exceeds $7 c$ involves only localised shear failure around the anchor, and as a result the ultimate capacity effectively becomes a function only of the undrained shear strength of the soil.

KEYWORDS: anchors; design; failure; numerical modelling and analysis; plasticity; pore pressures; suction; shear strength
Nous examinons dans cette étude le comportement d'ancres en bande horizontales enfouies dans de l'argile. Nous présentons une brève critique des diverses méthodes suggérées pour la conception de ces ancres, en insistant sur l'estimation de la charge ultime que ces ancres peuvent supporter lorsque ces ancres sont chargées rapidement dans des conditions de redressement non drainées. Nous passons en revue les éventuels mécanismes de défaillance, dont la défaillance de cisaillement et de traction dans le sol et le développement d'une succion dans le fluide interstitiel, et nous comparons les résultats des prédictions d'éléments finis avec les données expérimentales pour des charges ultimes. Les analyses révèlent que le comportement d'ancres en bandes lors du redressement est fonction des paramètres non dimensionnels suivants : $H / B, y H / c$ et $u_{\mathrm{c}} / \mathcal{c}, H$ étant la profondeur d'enfouissement de l'ancre, $B$ étant la largeur de l'ancre, $y$ étant le poids unitaire du sol, $c$ étant la résistance de cisaillement non drainé et $u c$ étant la magnitude de l'eau de pore dans le sol. Il est démontré que la capacité de redressement ultime dépend de la disponibilité de l'eau à la surface du sol et à l'intérieur du sol sous l'ancre en bande. Les analyses montrent aussi que les ancres enfouies peu profondément dans des sols relativement forts ont tendance à être déficientes à cause du développement de défaillance de résistance à la traction dans le sol audessus de l'ancre. La capacité ultime de ces ancres peu profondes est fonction de la résistance au cisaillement non drainé du sol, de son poids propre et de la capacité de résistance à la traction du fluide de pore. Par contraste, le mécanisme de défaillance pour des ancres enfoncées profondément où la contrainte totale verticale initiale dépasse $7 c$ cause uniquement une défaillance de cisaillement localisée autour de l'ancre et en raison de la capacité ultime devient en fait fonction uniquement de la résistance au cisaillement non drainé du sol.

\section{INTRODUCTION}

The behaviour of horizontal or near horizontal buried anchors in vertical uplift loading is important to a number of engineering applications, including transmission tower anchors, variable geometry drag anchors, and other forms of marine anchor system. This paper provides a brief critique of the available approaches to the design of these anchors in clay when subjected to rapidly applied uplift loading--that is, under undrained conditions. Shortcomings of the current design methods are identified, and the results of analyses to allow a more rational design approach are provided.

Figure 1 shows the problem investigated and defines the key parameters. Most references (e.g. Meyerhof \& Adams,

Manuscript received 10 June 2003; revised manuscript accepted 22 July 2003 .

Discussion on this paper closes on 1 May 2005, for further details see p. ii.

* Department of Civil Engineering, The University of Sydney, Australia.

Faculty of Design, Architecture and Building, The University of Technology Sydney, Australia.

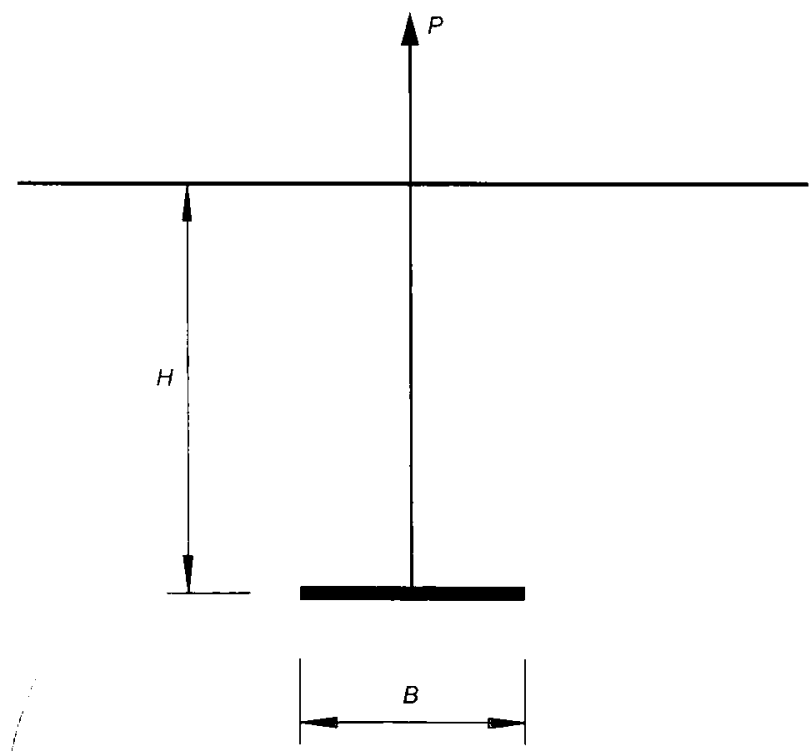

Fig. 1. Uplift of a strip anchor 
1968; Davie \& Sutherland, 1977; Sutherland, 1988) give the ultimate uplift capacity of a strip buried in a uniform cohesive soil and loaded under undrained conditions as

$$
P_{\text {ult }}=B\left(F_{C}+\gamma H\right)
$$

where $P_{\text {ult }}$ is the ultimate resistance in uplift per unit length of the strip anchor $(\mathrm{kN} / \mathrm{m}), B$ is the width of buried strip anchor $(\mathrm{m}), c$ is the undrained shear strength of the clay $(\mathrm{kPa}), F$ is the uplift capacity factor, $H$ is the depth of the strip below the surface $(\mathrm{m})$, and $\gamma$ is the total unit weight of soil $\left(\mathrm{kN} / \mathrm{m}^{3}\right)$. Some references, however, do not include the soil self-weight term (e.g. Das \& Singh. 1994; Forrest et al., 1995).

Rowe \& Davis (1982) and Merifield et al. (1999, 2001) use equation (1) but apply a limiting value for the capacity of a buried strip anchor. That is:

$$
P_{\mathrm{ult}}=11.42 B C
$$

Most of the analytical models in the literature, including the latter two, are based on weightless soil models with the effect of density superimposed. In their study Merifield et al. (2001) concluded that the errors incurred by assuming superposition are likely to be relatively insignificant for infinitesimal strain analyses. This paper presents analyses in which the soil density and other factors noted below are included in the initial analyses, i.e. superposition of the selfweight effect is not assumed a priori.

In this paper the results are presented for the uplift capacity $N_{c}$, defined as

$$
P_{\mathrm{ult}}=N_{\mathrm{c}} B c
$$

One of the major aims of the paper is to investigate the phenomena of tensile failure in the soil and the development of suction pore water pressures, and the influence they have on the ultimate capacity of strip anchors.

\section{MECHANISMS OF FAILURE}

Mechanisms of failure for various conditions

Uplift loading produces different stress changes in various regions of the soil. In the region below the strip anchor there is a reduction in the total vertical stress, whereas in the region immediately above the strip there is an increase in total vertical stress. The surface directly above the strip tends to bulge upwards, with the intervening soil acting as a form of beam. This 'beam' action results in a decrease in the horizontal stress that can lead to tensile stresses. Tensile failure is unusual in soil mechanics, though several authors have noted tensile cracking above the plate during loading in tests (e.g. Meyerhof \& Adams, 1968; Davie \& Sutherland, 1977; Rowe \& Davis, 1982). Rowe \& Davis (1982) noted that because of this cracking their analyses could not be used for shallow anchors. They did not provide alternative solutions for this situation.

The various mechanisms by which a rapidly loaded anchor may fail in uplift are depicted in Fig. 2. Figs 2(a) and 2(b) are for strips that separate from the soil beneath during loading, whereas Figs 2(c) and 2(d) are for anchors that have not separated from the soil beneath during loading.

Figure 2(a) shows a shallow anchor separated from the soil beneath. In this case the failure occurs as a result of shearing of the soil along lines directly above the edge of the strip (thus lifting the soil above the strip) and of tensile failure of the soil near the surface as a result of the 'beam' action.

Figure 2(b) shows the mechanism for a deep anchor separated from the soil beneath: in this case the mechanism of failure is shearing contained within the soil above the strip without surface effects. With the strip at great depth
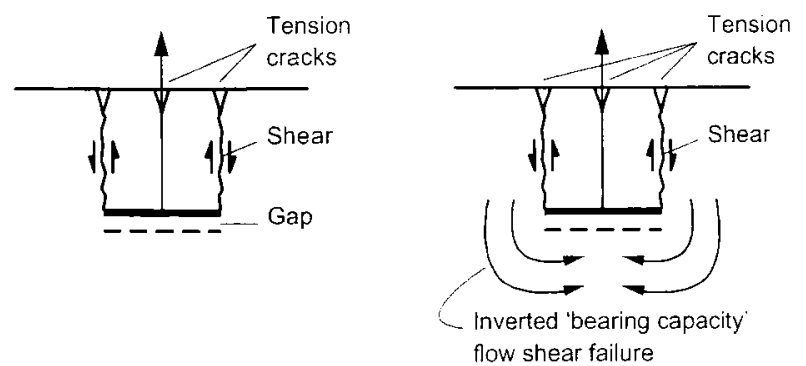

(a)

(c)

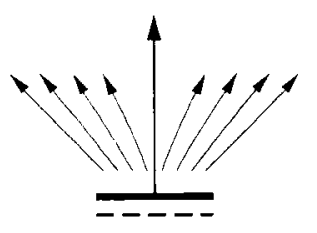

(b)

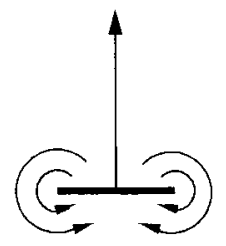

(d)
Fig. 2. Mechanisms of failure in uplift: (a) shallow anchor, separated from soil beneath; (b) shallow anchor, joined to soil beneath; (c) deep anchor, separated from soil beneath; (d) deep anchor, joined to soil beneath

there is no significant surface expression, and hence the 'beam' action is absent.

Figure 2(c) shows the mechanism for a shallow anchor bonded with the soil beneath. In this instance the failure is by tension near the surface resulting from 'beam' action. shearing between the strip and these tensile cracks, and shearing beneath and beside the strip in a form of "bearing capacity' failure as the soil beside the strip flows round to beneath the strip. As will be shown later, the self-weight of the soil is less important in this case.

Figure 2(d) shows the mechanism for a deep anchor bonded with the soil beneath. In this instance the soil flows around the strip, and the failure is in shear and is contained locally within the soil. It will be shown that, for this form of failure, the self-weight of the soil has no effect on the failure load.

Most of the published design methods show the value of either $F$ or $N_{\mathrm{c}}$ as a function of $H B$. At $H / B=0$, the value of $F$ or $N_{\mathrm{c}}$ is typically zero for the unbonded case or $5 \cdot 14$ for the bonded case, and increases to a maximum value of about 5.5-7.5 for the unbonded case as the anchor becomes buried. The corresponding values for the deeply buried bonded case are: for strips 11.42 , i.e. $3 \pi+2$, as in Meyerhof (1951) and Rowe \& Davis (1982); and, for circles, 12.42 and 13.11 for rough and smooth plates respectively (Martin \& Randolph, 2001). Solutions for deep square, circular and rectangular anchors have also been published by Merifield et al. (2003). The value of $H / B$ at which this maximum value is reached is called the critical depth ratio; it corresponds to the onset of the self-contained failure modes of Figs 2(b) and 2(d).

Forrest et al. (1995) and Das \& Singh (1994) give the critical depth to diameter ratio for buried circular plates. Das (1978, 1980) provides estimates of the critical embedment ratio for square and circular plates, given by the embedment depth divided by the plate size (side length or diameter). In all these studies this critical depth ratio is given as a function of the shear strength alone. The former gives the critical depth to diameter ratio as about 1.2 for $c=5 \mathrm{kPa}$, increasing to about 3.5 at $c=30 \mathrm{kPa}$. The corresponding 
values quoted by Das and Singh are 3 and 5.7. Das (1978) quotes values between 3 and 7 for circular and square plates over a similar range of strengths. For rectangular anchors Das (1980) indicates that the critical embedment ratio increases approximately linearly from the value for a square to a maximum of 1.55 times the value for a square when the plate has an aspect ratio of 3 or more. It must be kept in mind that Forrest et al. (1995) did not include overburden pressure in the expression for uplift capacity, whereas the papers by Das do include it.

These empirical relationships of critical depth to diameter ratio with soil strength are plotted in Fig. 3, together with data from other workers. The differences between the two curves for circular plates can be ascribed to different plate sizes and conditions, though both are from relatively smallscale experiments. It may be significant that Forrest et al. (1995) recommend that plate anchors should be installed to a depth of at least 5 diameters. It is also clear from Fig. 3 that neither curve is very reliable for other data.

It will be shown that the concept of a straight-line relationship up to a 'critical depth' is an oversimplification. In addition, the onset of the 'deep' failure load is shown to be a function of the size (either $H$ or $B$ ), the soil density and the shear strength, plus the ability of the surface soil and the soil beneath the plate to accept tension.

\section{Factors affecting separation}

When uplift loading is applied, the (total) contact stresses beneath the plate decrease. With rapid loading this results in a decrease in the pressure in the pore fluid. Whether the strip will separate from the soil or not as a result depends on the physical conditions.

If the underside of the strip is connected to the outside air, or if the pore fluid cannot sustain tension, the strip will separate from the soil when the total stress reduction equals the initial total stress. Pores containing large proportions of air, or pore fluids with high dissolved gas contents, may be

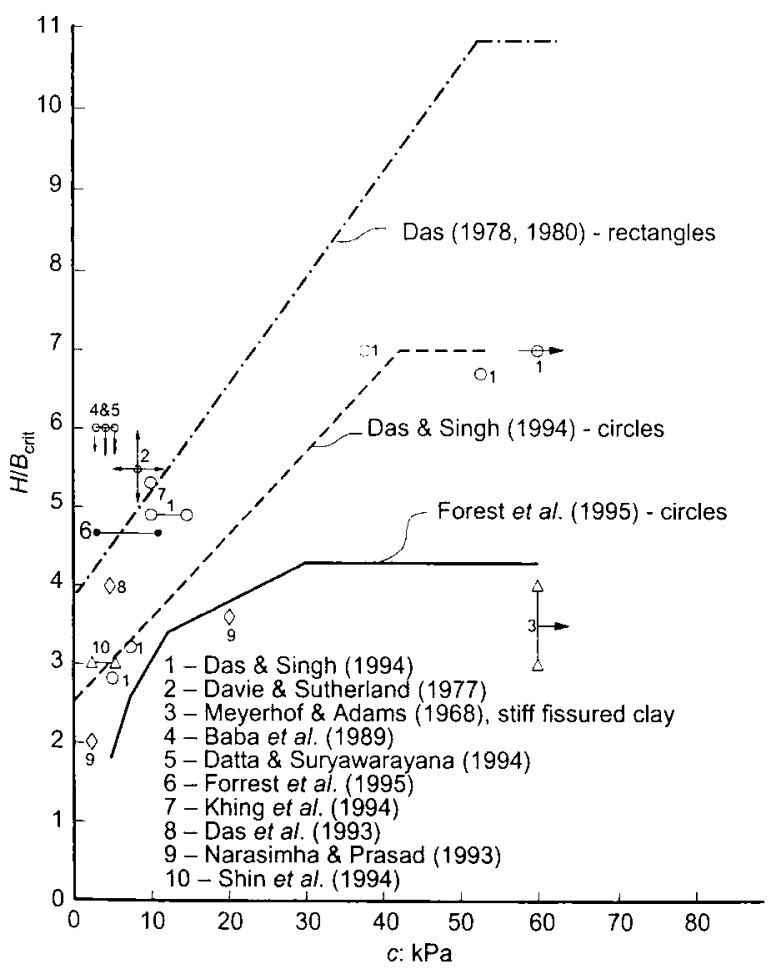

Fig. 3. Test data illustrating the effect of shear strength on the critical depth ratio for circular, square and rectangular anchors unable to sustain significant tension. This may be an important consideration for plate anchors embedded in some seabed soils, where gas contents, especially methane, may be significant.

If the soil is saturated, and the underside of the strip is open to water at the same hydrostatic level as the pore water, then separation will take place when the pressure reduction equals the initial effective overburden pressure.

In a saturated soil where the strip is sealed within the soil, separation cannot occur unless either:

(a) the pore pressures equalise by dissipation of the induced pore pressures, in which case an undrained analysis is invalid, as the loading is no longer 'rapid', or

(b) the pore pressure drops far enough below atmospheric for cavitation to occur-that is, failure in tension of the pore contents.

Estimates of the rate of dissipation of pore pressure around a plate can be made by the methods described in Booker \& Small (1987) to test the assumption of undrained behaviour. Some other relevant information is also contained in Pyrah et al. (1985) and Small et al. (1998). A discussion of the effects of failure in tension of the pore contents is given below in the section 'Effect of allowable pore water pressure tension on uplift capacity'.

Factors affecting soil tensile capacity near the soil surface

The concept of soil operating in tension is somewhat unusual. Finite element analyses in which tension was allowed showed a drop in total horizontal stress near the surface of approximately $100-160 \%$ of the shear strength. Although unsaturated soils can have some tensile strength in total stress terms, it is certainly not of this magnitude. Meyerhof \& Adams (1968) indicated that tests on soft clays had given a tensile strength of $40 \%$ of the compressive strength but did not give any further details, and it is possible that this strength came from negative pore water pressures. Tests on unsaturated compacted clays gave tensile strengths in Brazilian tests of $25-78 \mathrm{kPa}$, and all the samples in these tests had unconfined compression strengths in excess of $500 \mathrm{kPa}$.

In saturated soils the presence of the pore water will allow some total stress tension to be sustained, and in a true undrained situation some tensile total stresses should be able to be accommodated. The tensile stresses caused by uplift of a strip are, however, right at the surface, and any negative pore water pressures could dissipate almost instantaneously provided there is free water at the surface. As a crack forms, only the soil at the very tip would need to drain for the crack to propagate. Such dissipation would occur at many orders of magnitude greater than dissipation for the pore pressures in the soil beneath and around the strip, and the view has been taken that pore pressures at the base of a crack from the surface will not drop below initial (hydrostatic) values.

\section{ANALYSES UNDERTAKEN}

Analyses of strip anchors in clay subjected to undrained uplift loading were undertaken using the finite element program AFENA (Carter \& Balaam, 1995). The analyses assumed a thin, perfectly rigid strip, progressively displaced until failure occurred. Large-strain analyses were undertaken with re-meshing using an automatic mesh generation program developed by $\mathrm{Hu} \&$ Randolph (1998). Most of the analyses were carried out assuming a smooth plate. Some check analyses with rough plates showed that the differences 
were very minor. Two different soil models were used in this study.

In the first model, the soil was represented as a singlephase material, characterised by a shear strength, a tensile strength, Poisson's ratio, shear modulus and density (unit weight). In these analyses the tensile strength was taken as either very large or zero. For the analyses with zero tensile strength, if the minor principal (total) stress reduced to zero, the stresses at that Gauss point were maintained at that same value for all subsequent steps in the non-linear analysis. Poisson's ratio was always 0.49 to approximate constantvolume deformation and the ratio of shear modulus to shear strength $(G / C)$ was 67 , except for some analyses that were undertaken to examine the effect of changing this ratio.

In the second model, the soil was represented as a twophase material. One phase was the soil skeleton, characterised by a shear strength, a tensile effective strength, effective Poisson's ratio, shear modulus and total density (unit weight). The second phase was the pore water, characterised by a very large bulk modulus, zero shear strength and stiffness, and with a limiting value for the negative pore pressure allowable. General details of the two-phase method can be found in some textbooks (e.g. Naylor et al., 1981). In these analyses the soil tensile strength (measured in terms of effective stress) was taken as zero, and soil tension was dealt with in the same manner as for the single-phase soil. Various values were assigned to the limiting negative pore pressure. For the pore fluid, if the pore pressure dropped below a value of $-u_{c}$, the pore pressure was maintained at that value and the bulk stiffness was set to zero. The formulation can handle effective stress soil strength parameters, but, for the purpose of this work, a uniform strength was required, and so the artifice was used of giving the soil a cohesion only. The ratio of shear modulus to shear strength was kept as 67 , as for the single-phase soil Poisson's ratio of the solid skeleton was taken as 0.25 , and for most analyses the total unit weight of the soil was taken as $20 \mathrm{kN} / \mathrm{m}^{3}$ and the unit weight of the water was taken as $10 \mathrm{kN} / \mathrm{m}^{3}$.

Both methods allow failure of the soil in tension. If the minor principal stress drops to zero the soil stresses are frozen and any requirement for zero volume change ceases, even in the two-phase soil. This is not strictly correct, because the major principal stress could theoretically continue to increase after tensile failure to $2 c$ (or perhaps even larger if a truly frictional soil model had been assumed). This is likely to result in some underestimate of the capacity of shallow anchors with low values of $\gamma H / c$.

In the two-phase soil, if the pore water pressure reduces to below $-u_{c}$ then the no volume condition ceases and any further stress changes are transferred to the soil skeleton and the pore pressure is kept at $-u_{\mathrm{c}}$.

Results of analyses are presented for the following cases.

1. Single-phase soil model, total stress tension allowed in all soil elements and tension allowed at the interface between the soil and the underside of the strip anchor.

2. Single-phase soil model, total stress tension allowed in all soil elements but with a no-tension joint immediately beneath the strip anchor.

3. Single-phase soil model with no total stress tension allowed anywhere in the soil.

4. Two-phase soil model with soil tensile failure if the minor principal effective stress reduces to zero. Above the strip no reduction in pore pressure below the initial pore pressure is allowed, whereas below the strip the total pore pressure is not allowed to reduce below zero (i.e. cavitation limit, $u_{\mathrm{c}}=0$ ).

5. Two-phase model with the soil above the strip as for
Case 4 but with no cavitation limit for the soil beneath the strip (i.e. $u_{c}$ large).

6. As for Case 5 but with varying cavitation limits

Cases 1 and 2 do not have much physical validity, if any, but are included to allow comparison with other results and to demonstrate the effect of tensile failure on uplift capacity.

Analyses for case 1 using small-strain theory showed that the uplift capacity factor was independent of the soil strength, normalised as $\gamma H / c$. Large-strain analyses were also undertaken to assess the extent to which work done against gravity might influence results. Figure 4 shows the results of comparing large- and small-strain load deflection curves for a relatively shallow anchor $\left(H^{\prime} B=1\right)$. For anchors with $H / B>2$ the differences were negligible. Even for shallow anchors it was concluded that, although for very weak soils the large-strain results showed higher capacities, these higher capacities occurred at very large deformations, and for practical deformations the small-strain result was considered acceptable. Likewise, for high-strength soils, slightly lower capacities were recorded for very shallow anchors, but the difference was only $8 \%$ in the worst case. Large-strain analyses for case 2 , which assumes no bonding between the underside of the strip and the soil, but allows tension in the soil itself, also showed similar differences between largeand small-strain answers, and also showed that the smallstrain results were acceptable. The large-strain results did highlight the brittle nature of failure in higher-strength soils.

These results also showed that the inclusion of a density term in the expression for ultimate capacity, as in equation (1), is not required, and that equation (3) is more appropriate for expressing the anchor capacity. The results of case 2 showed that if $\gamma H / c<7$, the mechanisms of failure were similar to Figs 2(a) and 2(b), whereas for greater values of $\gamma \mathrm{H} / \mathrm{c}$ the behaviour was identical to that of a fully bonded anchor.

The results of other cases are dealt with in later sections.

\section{APPLICABILITY OF ANALYSES TO FIELD SITUATIONS Unsaturated soils}

Many applications of buried anchors involve unsaturated soils, including transmission tower anchors and the like. In most instances these will be buried in compacted clays, because of the difficulty of installing a horizontal anchor plate in undisturbed soil. Because of the air in the pore fluid, it is reasonable to assume that the soil near the surface will fail in tension if the total stress drops below zero. Beneath

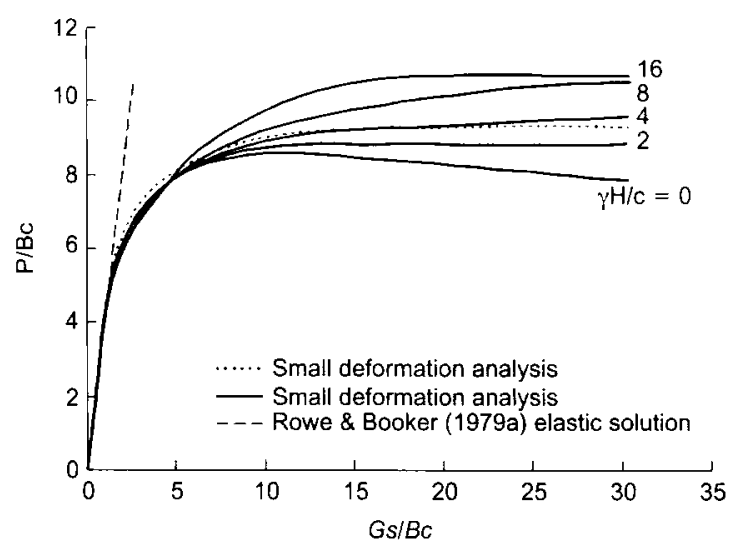

Fig. 4. Load-deflection curves for large and small deformation analyses of fully bonded, tension allowed soil (case 1 ), $H / B=1$ 
the plate the soil and plate would part if the total stress dropped below zero, though the extent will depend on the proportion of air and the speed with which air can get access to the underside of the strip. Unless other information is available, for example the results of full-scale tests at the same site, a reasonable approach is to assume that no total stress tension can be tolerated beneath the plate. Thus the analyses of case 3 (the single-phase soil no-tension analysis) would be adopted.

Caution needs to be exercised if the surface is exposed, as drying tension cracks could reduce the uplift capacity.

\section{Saturated soil}

In saturated soils, separation will occur only if the effective stress beneath the plate drops below zero. This can occur only if the negative pore pressures beneath the plate dissipate (unless cavitation occurs; see below). If dissipation occurs then the surrounding soil will also have drained, and the undrained analysis solutions are no longer applicable. On

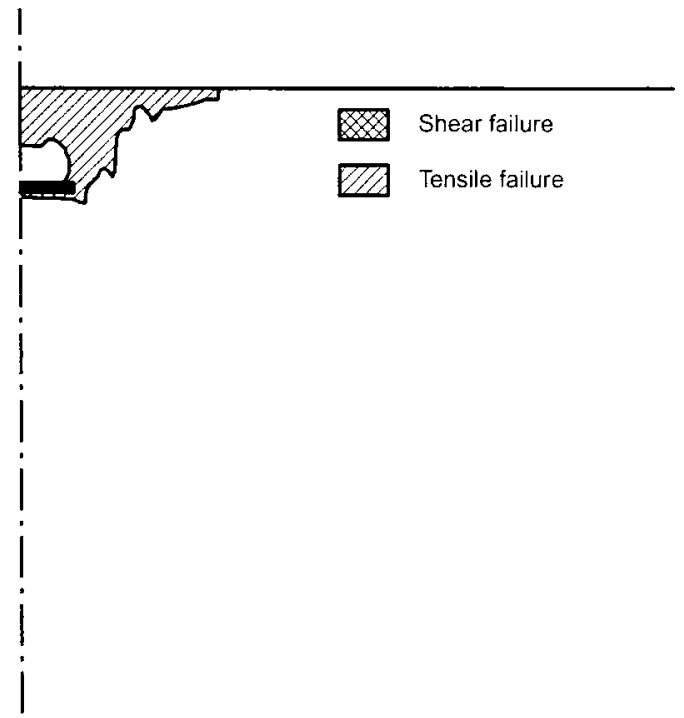

(a)

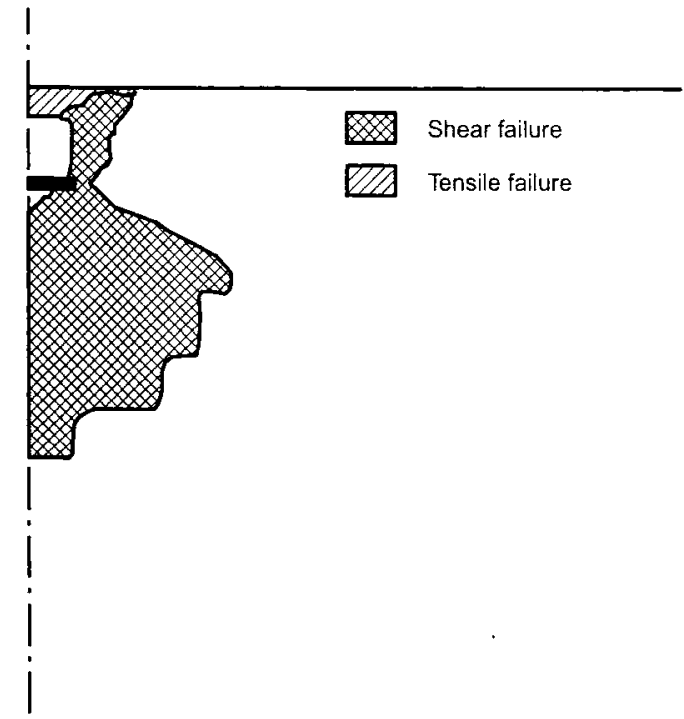

(b) the other hand dissipation of the negative pore pressures in the tensile zone near the surface could occur much more rapidly, as discussed above.

It is therefore concluded that for design in such circumstances the results for case 5 (the two-phase soil, large $u_{c}$ analysis) should be used. It is also necessary to check for cavitation. In deep water and weak soils this will not be a problem, but in other cases a check should be made using the methods described subsequently in the section 'Effect of allowable pore water tension on uplift capacity'.

\section{RESULTS FOR ANCHORS IN A SINGLE-PHASE SOIL (CASE 3)}

The distributions of shear and tensile failure in the soil are shown in Figs 5(a)-5(d). Figures 5(a) and 5(b) show results for relatively shallow anchors with $H / B=1$. Figure 5 (a) is for a relatively strong soil, $\gamma H / c=1$, whereas Fig. 5 (b) is for $\gamma H / c=8$, which approximates a normally consolidated soil. It can be seen that, for the strong soil, the

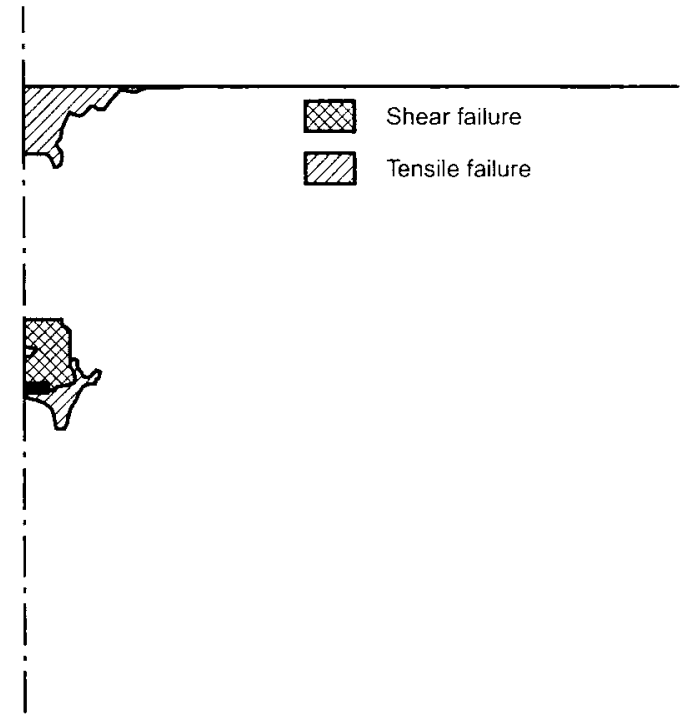

(c)

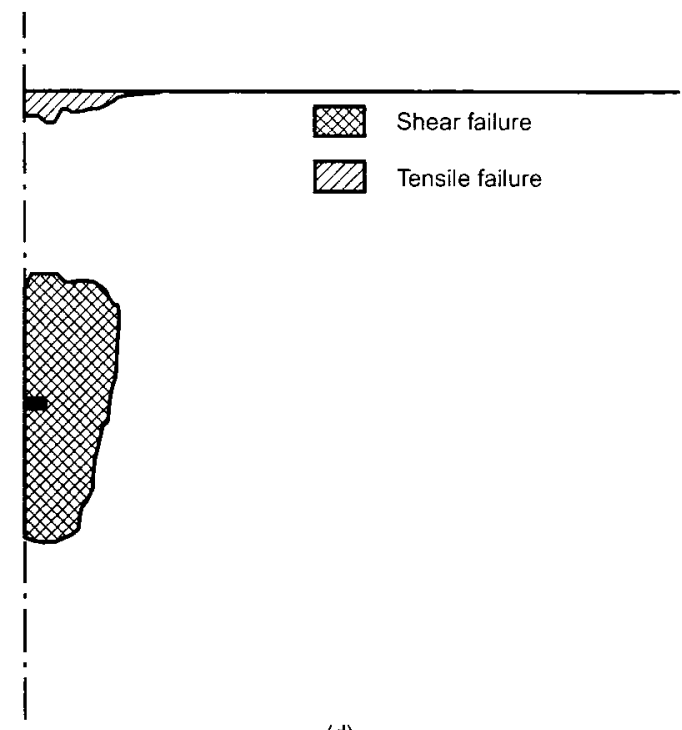

(d)

Fig. 5. Typical failure zones predicted by single-phase, no-tension analysis (case 3): (a) $H / B=1, \gamma H / c=1$; (b) $H / B=1, \gamma H / c=8$; (c) $H / B=6, \gamma H / c=1$; (d) $H / B=6, \gamma H / c=8$ 
tensile stresses near the surface cause failure from the surface to the plate. Thus the failure is all tensile, and the plate separates, whereas for the normally consolidated soil separation does not occur, and the failure is mostly in shear. although there is some tensile failure near the surface.

Figures $5(\mathrm{c})$ and $5(\mathrm{~d})$ show deep strips with $H / B=6$, again for the same two values of $\gamma H / c$. In these relatively deep anchors tensile failure still occurs at the surface but does not join the failed sections around the strip. For the relatively strong soil the strip separates from the soil beneath: tensile failure or splitting occurs next to the strip. and shear failure occurs above the strip. In the normally consolidated soil only shear failure is predicted to occur near and immediately above the strip.

These figures demonstrate the importance of the two nondimensional parameters $H / B$ and $\gamma H / c$ in determining the way that failure occurs and hence the load deflection and ultimate load behaviour. It was found that the relative stiffness (or 'rigidity index'), $G / c$, did not affect the anchor plate behaviour to any significant degree; this ratio was 67 and Poisson's ratio was 0.49 for all results given in this section.

The ultimate values for the uplift parameter $N_{\mathrm{c}}$ are shown in Fig. 6 as a function of $H / B$ for various values of $\gamma H / c$. Also included are the values for the tension-allowed analysis with a no-tension joint beneath the strip (case 2). As tensile failure is included beneath the anchor for both cases, the differences between the two sets of curves are caused by the tensile failure near the soil surface. The percentage reduction in ultimate capacity resulting from tensile failure above the strip depends on $\gamma H / c$, and for most values of $H / B$ ranges typically from $30 \%$ at $\gamma H / \mathrm{C}=1$ to less than $10 \%$ when $\gamma H / c=3$ and to less than $5 \%$ when $\gamma / H / c$ is 6 or more.

The capacity of the soil above the strip to accept a reduction in horizontal stress is also dependent on the initial in-situ value of the ratio of total horizontal and total vertical stresses, denoted here as $K_{\mathrm{t}}$. Clearly a large value of $K_{\mathrm{t}}$ results in higher initial horizontal stresses and hence a greater capacity to accept horizontal stress reductions before the stresses become tensile. A greater value of $K_{t}$ gives higher capacity: for example, in the cases where $K_{\mathrm{t}}=1$ and 0.9 , the uplift capacity factors for anchors with $H / B=1$ and $\gamma H / c=4$ are 5.61 and 5.55 respectively. The factors shown in Fig. 6 are for $K_{\mathrm{t}}=1$.

The nature of the load-deflection curve to failure is also dependent on $H / B$ and $\gamma H / c$. Fig. 7 shows some typical nondimensional load-deflection curves presented as $P / B C$

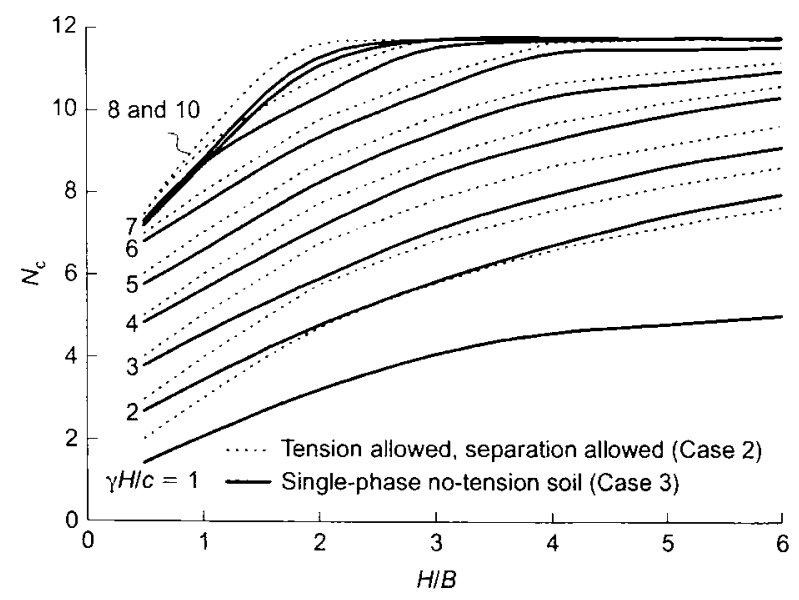

Fig. 6. Uplift capacity against $H / B$ for single-phase, no-tension soil (case 3) compared with tension-allowed soil with separation (case 2)

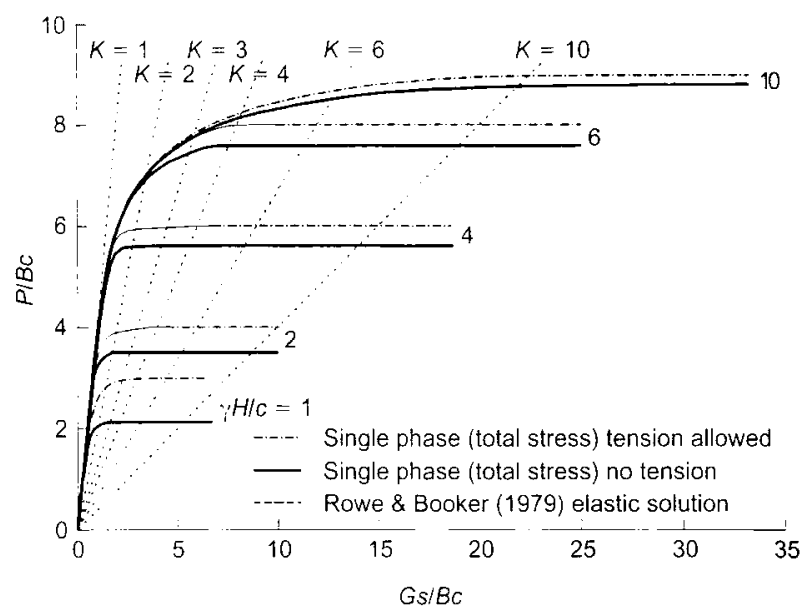

(a)

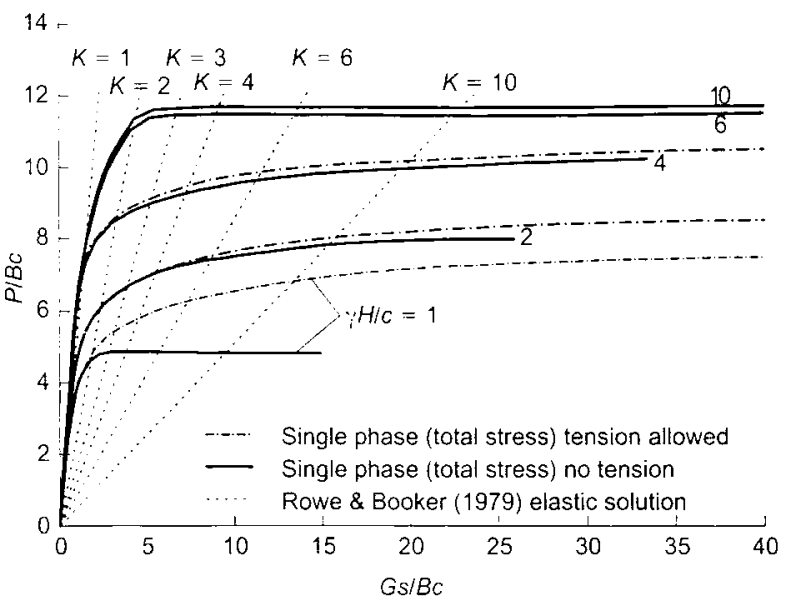

(b)

Fig. 7. Load-displacement curves predicted by single-phase, notension analysis (case 3 ): (a) $H / B=1$; (b) $H / B=6$

against $G s / B c$, where $s$ is the strip deflection and $P$ is the applied force. Rowe \& Booker (1979) give a method of calculating the elastic deflections, and these are also shown in Fig. 7. It is convenient to give the deflection to failure as a ratio $K$ of the deflection at failure to the deflection that would occur if the soil had remained elastic up to that load. Table 1 shows the results for a range of values of $H / B$ and $\gamma H / c$. It should be noted that, with strong soils $(\gamma H / c=1)$, sudden failure occurs at relatively low deflections. For shallow anchors in weak soils $(\gamma / H i c \geqslant 8)$, very large deflections may be required to attain the ultimate load, as is also the case for deep anchors of intermediate strength $(2<$ $\gamma H / c<4)$

The distribution of pressure across the strip is important for the design of real anchors. The distribution of load across the strip is shown in Fig. 8 in non-dimensional form as net vertical pressure normalised by the stress quantity $(P / B)$. Figure $8(a)$ is for loads of one-third the ultimate, and all the curves are very similar, with significant stress concentrations near the edge. This is an important consideration in the structural design of an anchor, because most anchors will work in this range of loading. By contrast, Fig. 8(b) shows the distribution at failure. In this case, the distribution is relatively uniform except for the case of a shallow anchor $(H / B=1$ in strong soil, $\gamma H / c=1)$. Fig. 8(c) shows the reduction in stress beneath the anchor at failure for cases where the anchor does not separate. It will be seen that in both cases the reduction is from 6 to 7 times the shear 
Table 1. Failure deflection ratio. $K$, predicted by single-phase analyses

\begin{tabular}{|c|c|c|c|c|c|c|}
\hline \multirow[t]{2}{*}{$\gamma H c$} & \multicolumn{3}{|c|}{ Tension allowed above plate (case 2) } & \multicolumn{3}{|c|}{ Vo tension (case 3) } \\
\hline & $H B=1$ & $H / B=3$ & $H / B=6$ & $H B=1$ & $H P=3$ & $H / B=6$ \\
\hline $\begin{array}{r}1 \\
2 \\
4 \\
6 \\
8 \\
10\end{array}$ & $\begin{array}{r}4 \\
4 \\
4 \\
5 \\
8 \\
10\end{array}$ & $\begin{array}{l}7 \\
6 \cdot 5 \\
6 \\
6 \\
5 \cdot 5 \\
5\end{array}$ & $\begin{array}{r}16 \\
14 \\
10 \\
4 \\
3 \\
3\end{array}$ & $\begin{array}{l}3 \\
3 \\
3 \\
4 \\
7 \cdot 5 \\
10\end{array}$ & $\begin{array}{l}3 \\
4 \\
5 \\
5 \\
5 \\
5\end{array}$ & $\begin{array}{r}3 \\
10 \\
9 \\
3 \\
3 \\
3\end{array}$ \\
\hline
\end{tabular}

strength. This is similar to the value noted in Rowe \& Davis (1982).

\section{RESULTS FOR ANCHORS IN A TWO-PHASE SOIL (CASES 4 AND 5)}

As noted above. the analyses for cases 4 and 5 used a two-phase soil model. All calculations assumed that Poisson's ratio of the soil skeleton was $0 \cdot 25, K_{0}=1 \cdot 0$, the total unit weight of soil was $20 \mathrm{kN} / \mathrm{m}^{3}$, and the unit weight of pore water was $10 \mathrm{kN} \mathrm{m}^{3}$. The calculations are not especially sensitive to Poisson's ratio but are affected by $K_{0}$ and the density insofar as they affect the initial horizontal effective stress. Common to both cases is the assumption that pore pressure dissipation at the base of a crack starting from the surface will be virtually instantaneous, and so tensile failure will occur when the reduction in horizontal stress equals the initial horizontal effective stress for the material above the strip.

Below the strip in case 4 it is assumed that the pore water cannot accept any negative pressure. This means that the strip will separate from the underlying soil when the total stress reduction beneath the strip equals the initial total vertical stress. In practice this is the same assumption as was made for the soil model for case 3 . Below the strip in case 5 it is assumed that the pore water can sustain any negative pore pressures without failure. In practice this means that the strip always stays in contact with the soil beneath it.

The mechanisms of failure for case 4 are very similar to those shown in Fig. 5, although the change from tensile to shear failure above the strip occurs at higher values of $\gamma H / c$. Likewise, the mechanisms of failure for case 5 always show shear failure beneath the strip but show similar mechanisms to case 4 above the strip.

Figure 9 shows the ultimate uplift values obtained for cases 4 and 5. It will be seen that, once $\gamma H / c$ exceeds 6 to 8 , there is little difference between the two predictions. This is because the value of the total vertical stress change below the anchor required to cause shear failure adjacent to and below the anchor is less than the initial total vertical stress, so tension does not occur beneath the anchor. At smaller values of $\gamma H / c$ the capacities for case 4 are substantially below those for case 5 . An interpolation method to deal with different values of the allowable negative pore pressure, $u_{\mathrm{c}}$, is given in the next section.

It is instructive to compare the ultimate values of $P / B C$ for case 3 with those for case 4 . In effect, in the former case the clay fails in horizontal tension above the plate when the horizontal stress reduction is the same as the total overburden pressure, whereas in the latter case the clay experiences failure at half this total stress reduction. This is also analogous to using the case 3 analysis with a $K_{\mathrm{t}}$ of 0.5 instead of 1.0 . The effect where $\gamma H / c=1$ (strong soil) is to reduce the ultimate load by about $30 \%$ at $H / B<4$, reducing to $14 \%$ at $H / B=6$. The reduction is under $10 \%$ where $\gamma H / c>3$

The distribution of load across the strip is shown in Fig. 10 in non-dimensional form as net vertical total pressure normalised by $P / B$. Figure $10(a)$ is for loads of one-third the ultimate, and all the curves are very similar, with significant stress concentrations near the edge. By contrast, Fig. 10(b) shows the distribution at failure. In this case the load is relatively uniform except for the case of a shallow anchor $(H / B=1)$ in strong soil $(\gamma H / c=1)$. Figure $10(\mathrm{c})$ shows the reduction in total stress beneath the anchor at failure where the anchor does not separate. It will be seen that in both cases the reduction is from 6 to 7 times the shear strength. All these distributions are very similar to those for the single-phase soil (Fig. 8).

The nature of the load-deflection curves for the twophase soil is similar to those for the single-phase soil. Table 2 shows the values of $K$ at failure-that is, the ratio of the deflection at failure to that which would occur at that load if the soil remained elastic. It should be noted that, with strong soils $(\gamma H / c=1)$, sudden failure occurs at relatively low deflections. For shallow anchors in weak soils $(\gamma H / c \geqslant 8)$, very large deflections may be required to attain the ultimate load, as is also the case for deep anchors of intermediate strength $(\gamma H / c=4)$.

\section{EFFECT OF ALLOWABLE PORE WATER TENSION ON UPLIFT CAPACITY}

For pure water at normal temperatures $\left(5-25^{\circ} \mathrm{C}\right)$ cavitation (boiling) will occur at a pressure of $80-95 \mathrm{kPa}$ below atmospheric. In clay soils, it is known that the water bound within the clay platelets can withstand much higher negative pressures. It is unlikely, however, that this would apply to the free water in the voids within the soil, and although more research is required to ascertain the actual behaviour, it is considered prudent to assume that pore water would also cavitate at pressures similar to normal water. The stress distributions in Figs 8(c) and 10(c) show that where separation does not occur the reduction in total stress below the strip is of the order of seven times the undrained shear strength. Thus cavitation can occur if the tolerable pore tension plus the initial pore pressure plus the initial effective vertical stress is less than seven times the undrained shear strength. In stiff soils this can occur, and it will be necessary to use a lower capacity if

$$
7 c>\gamma^{\prime} H+u_{0}+u_{c}
$$

where $u_{0}$ is the initial pore pressure above atmospheric $(\mathrm{kPa}), u_{c}$ is the (absolute) magnitude of the pressure drop below atmospheric at which water will cavitate $(\mathrm{kPa})$, and $\gamma^{\prime}$ is the submerged unit weight of the soil $\left(\mathrm{kN} / \mathrm{m}^{3}\right)$.

If $\left(\gamma^{\prime} H+u_{0}+u_{\mathrm{c}}\right)<7 S_{\mathrm{u}}$ then the capacity will be intermediate between case 4 and case 5 . Based on the analyses presented in the previous section, the reduced capacity caused by cavitation can either be approximated directly 


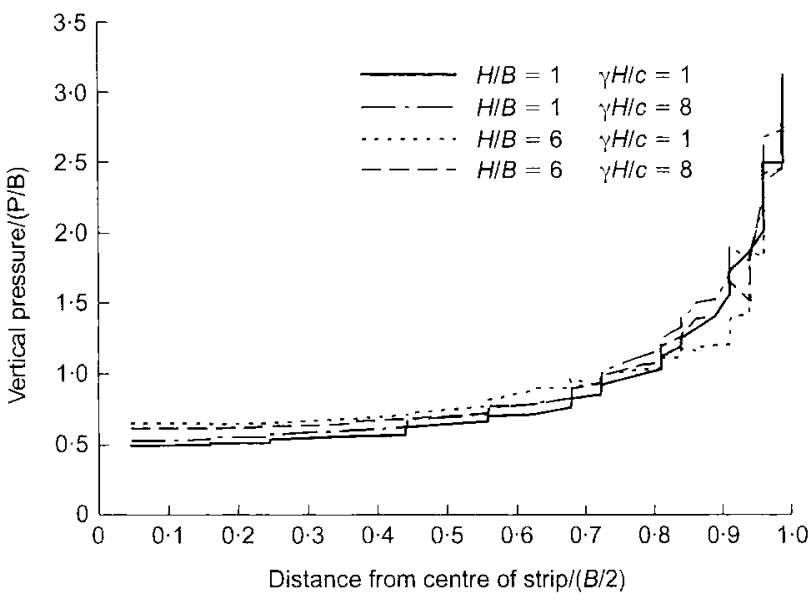

(a)

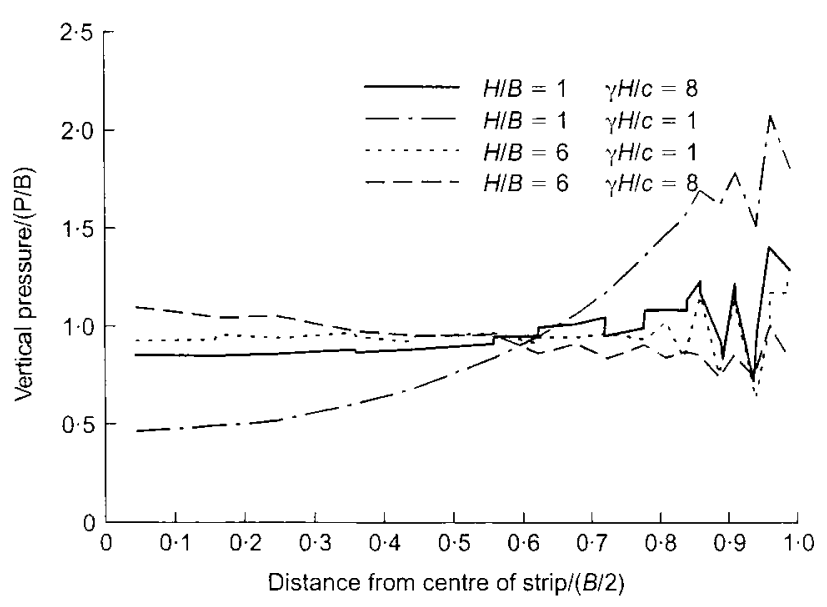

(b)

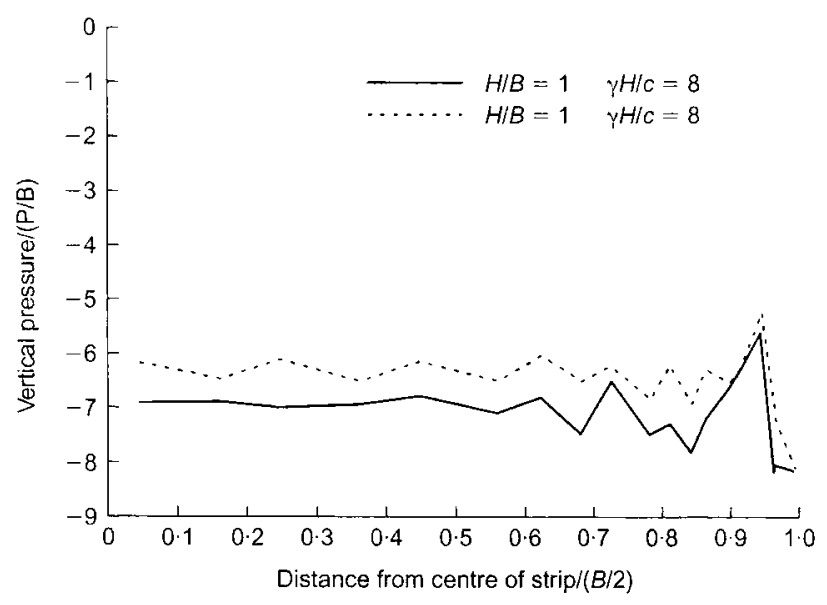

(c)

Fig. 8. Normalised stress distributions across the strip (case 3): (a) one-third ultimate load; (b) ultimate load; (c) net total stress change beneath strip

from the values given or, for other cases, this reduced capacity could be taken as

$$
P_{\text {ult }}=P_{4}+\left(P_{5}-P_{4}\right)\left(\frac{u_{0}+u_{c}-\gamma_{\mathrm{w}} H}{7 c-\gamma H}\right)
$$

where $P_{4}$ is the uplift capacity for case 4 , and $P_{5}$ is the uplift capacity for case 5 .

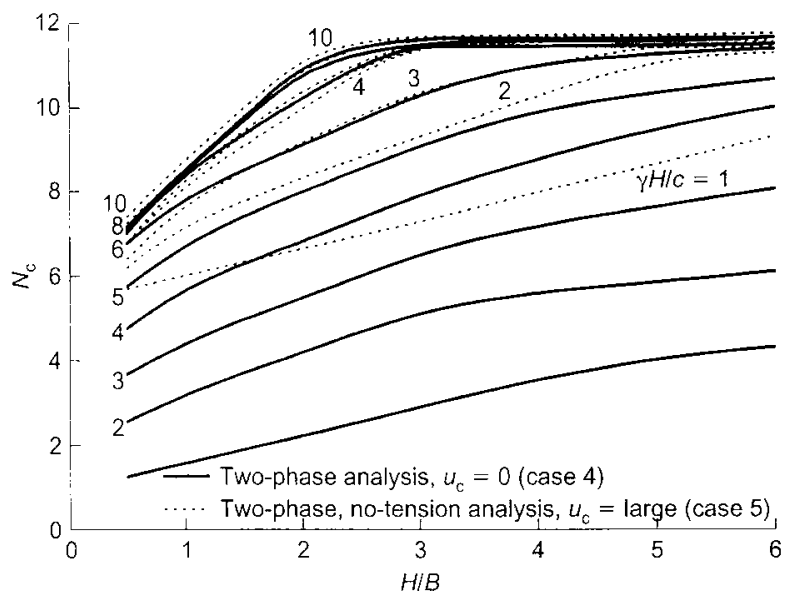

Fig. 9. Uplift capacity for no-tension, two-phase soil, $u_{\mathrm{c}}=0$ (case 4) and $u_{\mathrm{c}}=$ large (case 5 )

Equation (5) becomes unstable near the point where $\gamma H$ approaches $7 c$, as both the numerator and denominator in this equation approach zero, so some judgement is required.

Figure 11 shows a comparison of the results of finite element analyses as compared with the approximate predictions of equation (5). It can be seen that generally good agreement is obtained.

\section{COMPARISON WITH EXPERIMENTAL RESULTS}

Most of the experimental data in the literature are for the uplift of circular or square plates. Two sets of data for strips were found. Rowe \& Davis (1982) described experiments on $6 \mathrm{~mm}$ brass strips, $13-38 \mathrm{~mm}$ wide and $64-190 \mathrm{~mm}$ long. They indicated that there was little change in results once the aspect ratio $(L / B)$ exceeded 5, and that results for lower aspect ratios were slightly larger. The soil was a kaolin clay and was consolidated with an overburden pressure of $200 \mathrm{kPa}$ before unloading and testing, resulting in an average undrained shear strength of $50 \mathrm{kPa}$. Because of this preparation there would have been considerable initial horizontal pressures in the soil at the time of testing. Tension cracks were noted at $H / B$ values of less than $2 \cdot 5$. Figure 12 shows a comparison of calculations, made assuming an allowable reduction in horizontal stress at the surface of $50 \mathrm{kPa}$, with the experimental results. The test results are shown in Fig. 12 compared with calculations assuming that (1) the soil can take unlimited tension, and (2) the soil can sustain a $50 \mathrm{kPa}$ reduction in horizontal stress. This latter series showed only very small tension cracks for $H / B=3$ or more. It will be seen that the test results lie reasonably on the second line for shallow strips but nearer the first for higher values of $H / B$. It is noted that in the paper the opinion was given that the rods attached to the strip to apply the uplift loading accentuated the surface cracking.

Khing et al. (1994) reported results for a buried strip, $76 \mathrm{~mm}$ wide by $152 \mathrm{~mm}$ long and $13 \mathrm{~mm}$ thick, buried in clay with a liquid limit of $43 \%$, placed in a relatively wet condition to give an average shear strength of $10.2 \mathrm{kPa}$. The strip was sat on top of a Plexiglas box to prevent any contribution to the capacity by underlying soil. The soil was kneaded into place to exclude air bubbles. This placement method would have resulted in continual passive failure in the clay, with the result that the initial horizontal stress was close to twice the undrained shear strength. With such a high initial horizontal stress, tensile failure at the surface would not be expected. Figure 13 shows the experimental results together with those for calculations allowing tension 


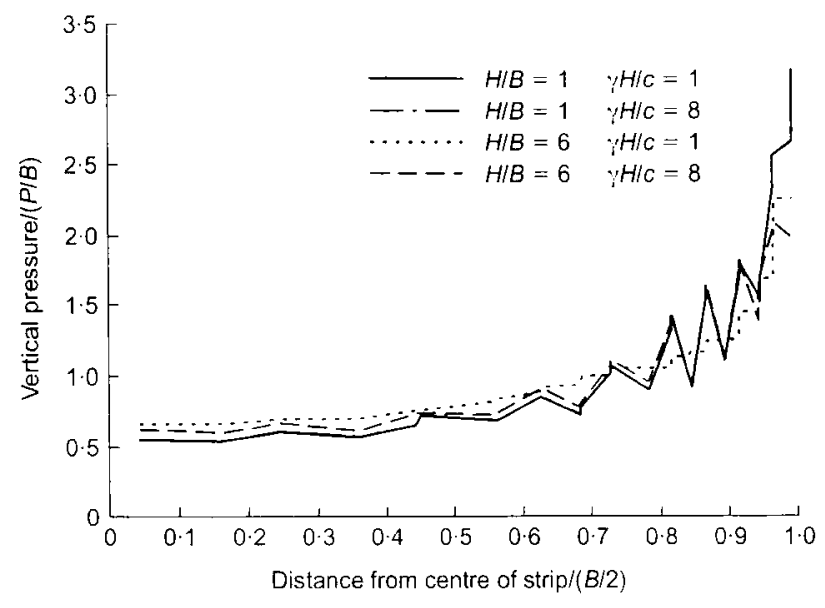

(a)

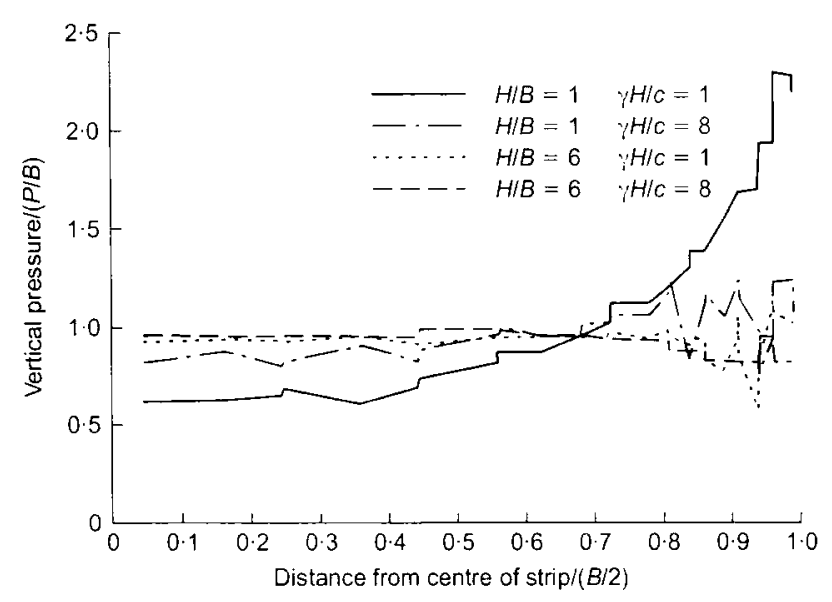

(b)

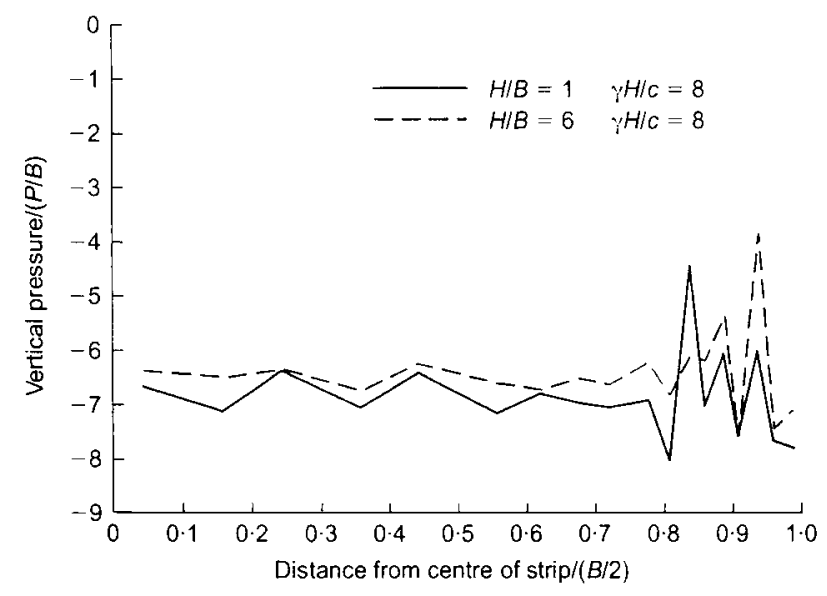

(c)

Fig. 10. Normalised stress distributions across the strip (case 4): (a) one-third ultimate load; (b) ultimate load; (c) net total stress change beneath strip to develop in the soil and plate separation (case 2), and there is reasonable agreement, although the experimental results are rather higher, as might be expected given their relatively low aspect ratio. The box beneath the strip would tend to inhibit failure at greater $H / B$ values because the soil could not move around to beneath the strip so readily.

\section{CONCLUSIONS}

(a) The analyses described in this paper show that the behaviour of strips in uplift is a function of the nondimensional parameters $H / B, \gamma H / C$ and $u_{\mathrm{c}} / c$. These represent the effects of depth of burial, the relative effects of overburden pressure and shear strength, and the capacity of the pore fluid to accept tension. At normal temperatures water can accept pressures in the region of $80-95 \mathrm{kPa}$ below atmospheric without vaporising. It is probable that this will also apply to water in macropores within a saturated soil, although more research is required to investigate this behaviour. Gas in solution could also limit the effective value of $u_{\mathrm{c}}$.

(b) The ultimate uplift capacity is dependent also on the availability of water at the soil surface and beneath the strip. Some guidelines for this are provided in the section 'Applicability of analyses to field situations', and in the discussion on separation in the subsection 'Factors affecting separation'. Designers need to consider the particular circumstances of their problem.

(c) In shallow anchors, failure in tension occurs from the surface downwards. The stronger the soil, the more likely is tensile failure, and the deeper the strip has to be before tensile failure does not occur.

(d) When anchors are deeply buried the failure pattern is a localised shear failure around the anchor, and the capacity becomes a function only of shear strength and is independent of the overburden pressure.

(e) The deflection at failure is very variable, as shown in Tables 1 and 2. In stronger soils, tensile failure results in low deflections at ultimate collapse, and overload could result in sudden failure. By contrast, for shallow anchors in weaker soils, the deflection to failure can be very high, and if deflections need to be limited, conservative factors of safety are required.

(f) Intuitively, it should be expected that the capacity of shallow anchors will be significantly affected by the magnitude of horizontal stresses prior to anchor loading. The limited results presented in this study confirm this expectation. In compacted clay fills high horizontal stresses commonly exist after placement, and can be as high as $2 c$. These may dissipate with time as the surrounding soil creeps away or as drying induces tension cracks in adjacent soil. Care is therefore necessary in interpreting the results of field tests on shallow anchors.

(g) The curves given in Figs 6 and 9 were computed for $\gamma$ $=20 \mathrm{kN} / \mathrm{m}^{3}$ and $\gamma_{\mathrm{w}}=10 \mathrm{kN} / \mathrm{m}^{3}$ and for $K_{\mathrm{t}}=1$. The

Table 2. Failure deflection ratio, $K$, predicted by two-phase, no-tension analyses

\begin{tabular}{|c|c|c|c|c|c|c|}
\hline \multirow[t]{2}{*}{$\gamma H / c$} & \multicolumn{3}{|c|}{$u_{c}=0($ case 4$)$} & \multicolumn{3}{|c|}{$u_{\mathrm{c}}=$ large $($ case 5$)$} \\
\hline & $H / B=1$ & $H / B=3$ & $H / B=6$ & $H / B=1$ & $H / B=3$ & $H / B=6$ \\
\hline $\begin{array}{r}1 \\
2 \\
4 \\
6 \\
8 \\
10\end{array}$ & $\begin{array}{l}2 \\
3 \\
3 \cdot 5 \\
5 \cdot 5 \\
10 \\
10\end{array}$ & $\begin{array}{l}3 \\
4 \\
5 \\
5 \\
5 \\
5\end{array}$ & $\begin{array}{c}3 \cdot 5 \\
4 \\
12 \\
5 \\
3 \cdot 5 \\
3 \cdot 5\end{array}$ & $\begin{array}{r}5 \\
6 \\
8 \\
9 \\
10 \\
12\end{array}$ & $\begin{array}{l}4 \\
4 \cdot 5 \\
7 \\
7 \\
7 \cdot 5 \\
7 \cdot 5\end{array}$ & $\begin{array}{l}3.5 \\
3.5 \\
3.5 \\
3.5 \\
3.5 \\
3.5\end{array}$ \\
\hline
\end{tabular}




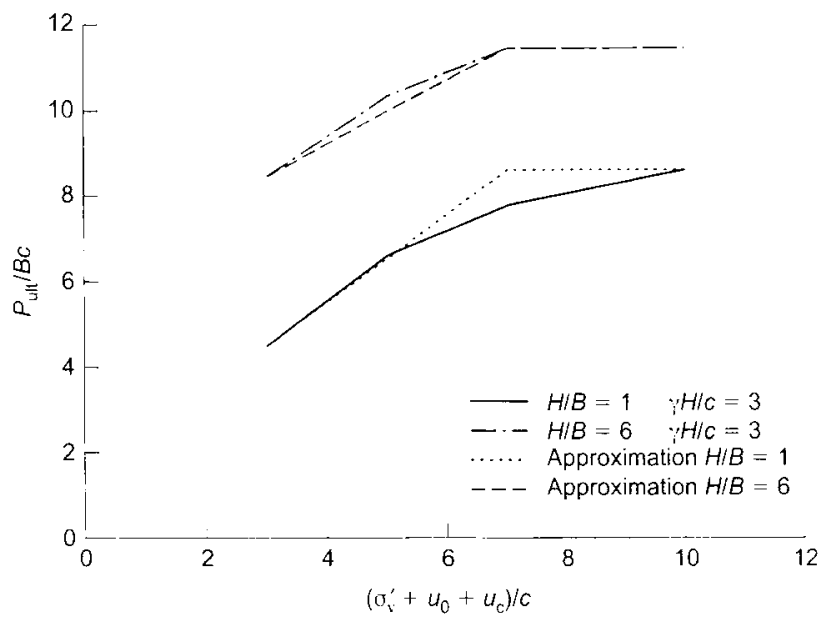

Fig. 11. Effect of the ability of the pore water to accept negative values on the uplift capacity, and comparison with predictions of equation (5)

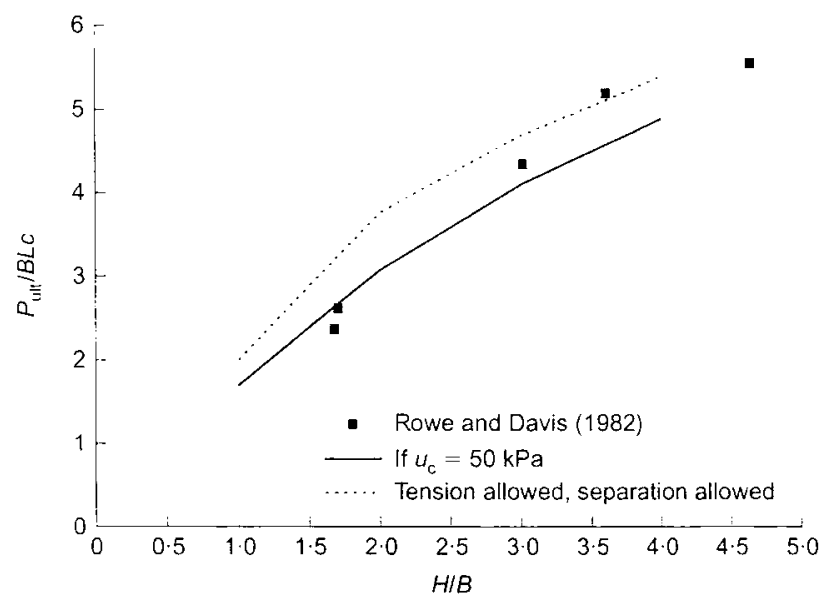

Fig. 12. Comparison of calculated values and experimental results from Rowe \& Davis (1982)

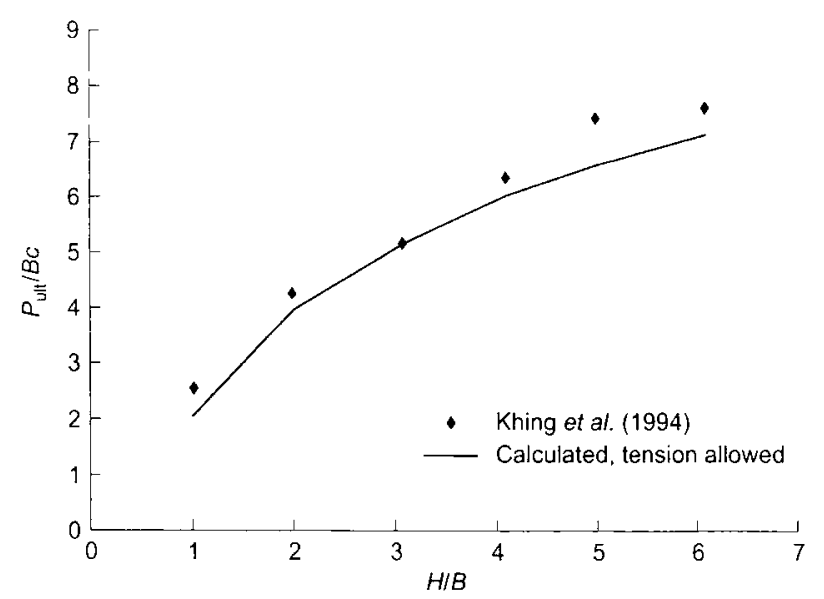

Fig. 13. Comparison of calculated values and experimental results from Khing et al. (1994)

effect of changing the soil density is simply reflected in the corresponding change in the parameter $\gamma H / c$. In situations where horizontal tensile failure occurs in the soil, the ultimate uplift capacity is likely to be sensitive to $K_{\mathrm{t}}$. (h) The predictions presented here indicate that reductions in the uplift capacity can be as much as $30 \%$ due to tensile failure of the soil (Fig. 6). This effect is most pronounced for anchors characterised by low values of the parameter $\gamma H / c$.

(i) Model tests in normal gravity have very low values of ${ }^{\prime} \mathrm{HC}$. In addition, many preparation techniques cause high initial horizontal stresses. Account must be taken of these factors when applying the results of such tests to full-scale design.

(j) In the normal working range of loading, there is a significant load concentration near the edge of the strip, and this needs to be taken into account in the structural design of strip anchors.

\section{ACKNOWLEDGEMENTS}

Some of the work described here forms part of the research programme of the Special Research Centre for Offshore Foundation Systems, established and supported under the Australian Research Council's Research Centres Programme. In addition, a Large Grant from the Australian Research Council to investigate the finite deformation behaviour of soils is also gratefully acknowledged.

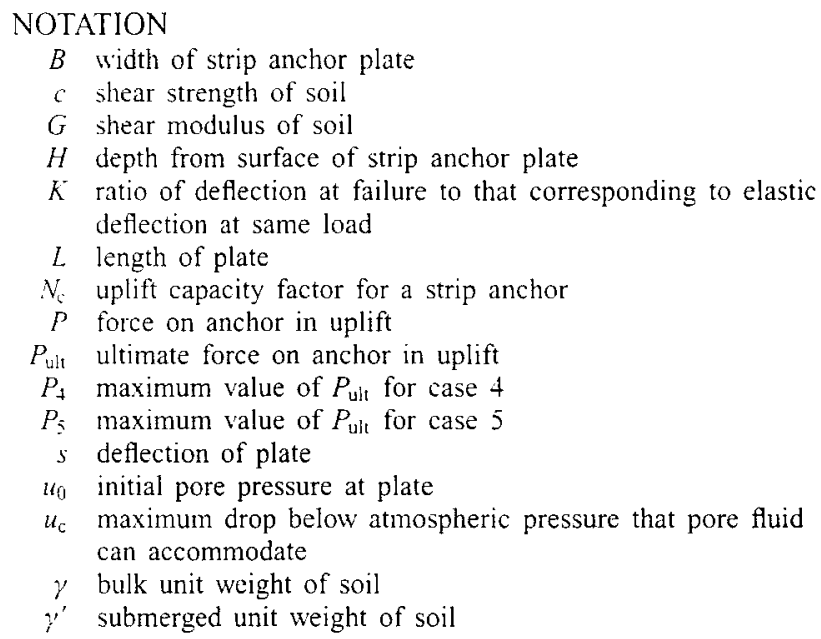

\section{REFERENCES}

Baba. H. U., Gulhati, S. K. \& Datta, M. (1989). Suction effect in plate anchors in soft clays. Proc. $12 \mathrm{th}$ Int. Conf. Soil Mech. Found. Engng, Rio de Janeiro 1, 409-412.

Booker, J. R. \& Small, J. S. (1987). The time deflection behaviour of a rigid under-reamed anchor in a deep clay layer. $I n t . J$ Numer. Anal. Methods Geomech. 11, 269-281.

Carter, J. P. \& Balaam, N. P. (1995). AFENA: Users' manual. Centre for Geotechnical Research, Department of Civil Engineering, University of Sydney, Australia

Das, B. M. (1978). Model tests for uplift capacity of foundations in clay. Soils Found. 18, No. 2, 17-24

Das, B. M. (1980). A procedure for estimation of ultimate capacity of foundations in clay. Soils Found. 20, No. 1, 77-82.

Das, B. M. \& Singh, G. (1994). Uplift capacity of plate anchors in clay. Proc. 4th Int. Offshore and Polar Engineering Conf., Osaka 1, 436-442.

Das, R. N., Shin, E. C., Das, B. M., Puri, V. K. \& Yen, S. C. (1993). Creep of plate anchors in clay. Proc. 3rd Int. Offshore and Polar Engineering Conf., Singapore 1, 538-543.

Davie, J. R. \& Sutherland, H. B. (1977). Uplift resistance of cohesive soils. J. Geotech. Div., ASCE 103, No. GT9, 935-952.

Datta, M. \& Suryanarayana, C. V. (1994). Elimination of suction beneath plate anchors in model tests: a comparison of two methods. Proc. 4th Int. Offshore and Polar Engineering Conf., Osaka 1, 456-459. 
Forrest, J., Taylor. R. \& Bowman. L. (1995). Design guide for piledriven plate anchors. Technical Report TR-2039-OCN, Port Hueneme, CA: Naval Facilities Research Center

Hu. Y. \& Randolph, M. F. (1998). A practical numerical approach for large deformation problems in soil. Int. $J$. Numer. Anal Methods Geomech. 22. 327-350 (see also Research Report G1226, Department of Civil Engineering, University of Western Australia, 1996)

Khing. K. H., Das. B. M. \& Yen. S. C. (1994). Uplift capacity of strip plate anchors in clay with sloping surface. Proc. 4th International Polar and Offshore Engineering Cont.. Osaka 1 . $467-471$.

Martin. C. M. \& Randolph. M. F. (2001). Applications of lower and upper bound theorems of plasticity to collapse of circular foundations. Proc I0th Int. Conf. on Computer Methods and Adrances in Geomechanics. Tucson 2. 1417-1428

Merifield. R. S., Sloan, S. W \& Yu. H. S. (1999). Stahility of plate anchors in undrained clav. Research Report No. 174.02.1999. University of Newcastle, Australia

Merifield, R. S., Sloan, S. W. \& Yu, H. S. (2001). Stability of plate anchors in undrained clay. Géotechnique 51, No. 2, 141-153

Merifield, R. S., Lyamin. A. V. Sloan, S. W. \& Yu. H. S. (2003). Three-dimensional stability analysis of plate anchors in clav. J. Gentech. Geoeniron. Engng. ASCE 29. No. 3, 243-253.

Meyerhof, G. G. (1951). The ultimate bearing capacity of foundations. Géotechnique 2, No. 4, 301-332.
Meverhof, G. G. \& Adams, J. I. (1968). The ultimate uplift of foundations. Can. Geotech. J. 5. No. +. 225-244.

Narasimha, S. \& Prasad, Y. V. S. N. (1993). Experimental studies on plate anchors in layered marine soils. Proc. 3rd Polar and Offshore Engineering Conf., Singapore 1, 544-550.

Naylor, D. J., Pande, G. N., Simpson, B. \& Tabb, R. (1981). Finile elements in geotechnical engineering. pp. 29-34. Swansea: Pineridge Press.

Pyrah, I. C., Hird. C. C. \& Tanaka. Y. (1985). Consolidation behaviour of a single underream anchor. Proc. $5 \mathrm{th} \mathrm{ht}$. Conf. on Numerical Methods in Geomechanics, Nagova. 629-636.

Rowe. R. K. \& Booker, J. R. (1979). A method of analysis for horizontally imbedded anchors in an clastic soil. Int. J. Numer: Anal. Methods Geomech. 3, 187-203.

Rowe, R. K. \& Davis, E. H. (1982). The behaviour of anchor plates in clay. Géotechnique 32, No. 1, 9-23.

Shin. E. C., Das. R. N.. Omar, M. T., Das. B. M. \& Cook, E. E (1994). Mud suction force in the uplift of plate anchors in clay. Proc. 5th Int. Offshore and Polar Engineering Conf., The Hague, Netherlands, 1, 462-466.

Small. J. S.. Thorne. C. P. \& Ta, L. (1998). Effect of pore pressure dissipation on the behaviour of plate anchors in clay. Proc. 8th Int. Polar and Offshore Engineering Conf.. Montreal. 497-504.

Sutherland, H. B. (1988). Uplift resistance of soils. Géotechnique 38, No. 1, 493-516. 


\section{GÉOTECHNIQUE}

VOLUME LIV NUMBER 8

OCTOBER 2004

www.geotechnique-ice.com

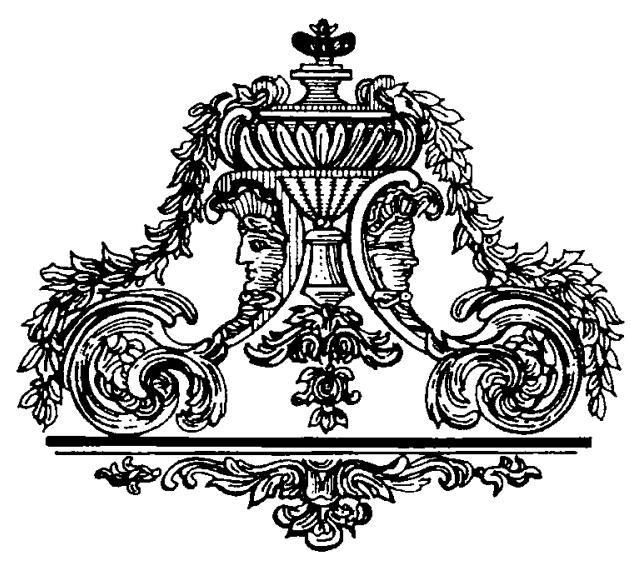

THE INSTITUTION OF CIVIL ENGINEERS

ISSN 0016-8505 


\section{GÉOTECHNIQUE}

Géotechnique publishes original papers and technical notes, in English and French, in the fields of soil and rock mechanics, engineering geology and environmental geotechnics. Case studies and papers that describe original work applicable to civil engineering practice are particularly encouraged. Papers to be considered for publication and requests for notes on the preparation of papers should be sent to Géotechnique, The Institution of Civil Engineers, 1-7 Great George Street, London SW1P 3AA (telephone: $+44(0) 207222$ 7722, fax: +44 (0)20 7665 2294). Author guidelines are also available at www.geotechnique-ice.com.

\section{DISCUSSION}

Discussions (maximum 500 words) are invited on papers and technical notes published in Géotechnique and should be sent to Géotechnique, The Institution of Civil Engineers, 1-7 Great George Street, London SW1P $3 \mathrm{AA}$. Contributors unable to meet the advertised closing date should inform Mary Henderson at the Institution of Civil Engineers (by airmail if overseas) of the day that the contribution will be received. Contributions, subject to the approval of the Advisory Panel, will be published in due course with the author's reply where appropriate.

\section{ADVERTISEMENTS \\ Advertisement enquiries should be made to DP Media, 6th Floor, Newminster House, 27/29 Baldwin Street, Bristol BS1 1LT.}

\section{COPYRIGHT}

All rights, including translation, reserved. Except for fair copying, no part of this publication may be reproduced, stored in a retrieval system, or transmitted, in any form or by any means electronic, mechanical, photocopying, recording or otherwise, without the prior written permission of the publishers. Or in the case of reprographic reproduction in accordance with the terms of licenses issued by the Copyright Licensing Agency in the UK or the Copyright Clearance Center in the USA.

\section{GÉOTECHNIQUE ON LINE}

Current and past issues of Géotechnique are available on line at www.geotechnique-ice.com.

\section{GÉOTECHNIQUE ARCHIVED ON CD}

A full text searchable archive of all papers published in the journal is now available. Géotechnique 50 contains all papers, discussion, technical notes and corrigenda published since the first issue in 1948. It is updated annually. For further details, contact the publishers, Thomas Telford (see below).

\section{VIRTUAL LIBRARY}

The ICE Virtual Library contains more than 20,000 illustrated papers published in the ICE Proceedings since 1936. The papers are available for download at $£ 15$ each (special discount for ICE members). For further information see www.iceknowledge.com.

\section{THOMAS TELFORD LIMITED}

Géotechnique is published monthly with the exception of January and July for the Institution of Civil Engineers by Thomas Telford Limited, 1 Heron Quay, London E14 4JD; telephone +44 (0)20 7987 6999; fax +44 (0)20 7538 9620, e-mail journals@thomastelford.com.

\section{DISCLAIMER}

Papers or other contributions and the statement made or opinions expressed therein are published on the understanding that the author of the contribution is solely responsible for the opinions expressed in it and that its publication does not necessarily imply that such statements and or opinions are or reflect the views of ICE Council or committees.

\section{SUBSCRIPTION RATES FOR 2004 (10 ISSUES)}

Annual subscription: $£ 298$ UK and Eire, $£ 343$ elsewhere (by air)

Special individual rate: $£ 95$ for 10 issues (provided that subscribers organisation also subscribes).

All payments and subscription inquiries should be made to the Journals Department, Thomas Telford Limited.

Overseas subscribers should remit by sterling draft payable in London.

Claims for non-receipt of issues must be made within four months of publication or they will not be honoured without charge.

Origination by Keytec Typesetting Limited, Bridport, Dorset

Printed and bound in Great Britain by Henry Ling Limited, at the Dorset Press, Dorchester, Dorset.

\section{ISSN 0016-8505}

(C) The Authors and the Institution of Civil Engineers 2004 


\section{GÉOTECHNIQUE}

OCTOBER 2004 VOLUME LIV NUMBER 8

\section{Editorial Advisory Panel}

Chairman and Honorary Editor

Professor G. T. Houlsby

University of Oxford, Oxford

Members

Dr C. Augarde

University of Durham, Durham

Dr J. A. Charles

Hertfordshire

Professor R. Lancellotta

Politecnico di Torino, Italy

Dr B. Littlechild

Dorset, UK

Dr R. E. May

Atkins Geotechnics, Surrey

Dr G. McDowell

University of Nottingham, Nottingham

Professor G. Pande

University of Swansea, Wales

Professor R. Pine

Camborne School of Mines, Cornwall

Professor H. F. Schweiger

University of Technology Graz, Austria

Dr K. Soga

University of Cambridge, Cambridge

Dr C. Thornton

University of Birmingham, Birmingham

Professor H-S Yu

University of Nottingham, Nottingham

Dr L. Zdravkovic

Imperial College of Science, Technology \&

Medicine, London

\section{Corresponding members}

Dr M. Almeida

Cidade Universitária Rio de Janeiro. Brazil

Professor E. T. Brown

Queensland Australia

Dr S.-S. Gue

Gue \& Partners, Malaysia

Professor O. Kusakabe

Tokyo Institute of Technology. Japan

Professor P. W. Mayne

Georgia Institute of Technology, USA

Publisher Mr L. Heward-Mills

Production Editor Mr R. Sands

Senior Secretary Mrs M. Henderson

\section{Contents}

507 Uplift capacity of rapidly loaded strip anchors in uniform strength clay

\section{P. Thorne, C. X. Wang and J. P. Carter}

519 Analyse tridimensionnelle en différences finies de l'interaction entre une structure en béton et le creusement d'un tunnel à faible profondeur

3-D finite difference analysis of the interaction between concrete building and shallow tunnelling

\section{O. Jenck and D. Dias}

529 Admissible stress fields and arching in piles of sand R. L. Michalowski and N. Park

\section{Technical Notes}

539 Microstructure in shear band observed by microfocus Xray computed tomography

M. Oda, T. Takemura and M. Takahashi

543 Seismic and static stability analysis for rock slopes by a kinematical approach

X.-L. Yang, L. Li and J.-H. Yin

551 Soil porosity from seismic velocities

S. Foti and R. Lancellotta

Discussion

555 Proposal for a new plasticity chart
E. Polidori 


\section{The Institution of Civil Engineers GÉOTECHNIQUE}

\section{Guidelines for authors}

Géotechnique, founded in 1948, is a journal that is published to inform a world-wide readership about fundamental developments and practice in geotechnical engineering. Géotechnique publishes entirely original papers, technical notes and discussions in the field of geotechnics, interpreted in the widest sense.

\section{Preparing a submission}

Papers submitted to Géotechnique must contain substantial original material and must not be submitted for publication elsewhere during the time they are being reviewed for Geotechnique.

\section{Format and copies}

Authors should supply three printed copies (one original and two duplicate copies) of their paper to Geotechnique, The Institution of Civil Engineers, 1-7 Great George Street, London SWIP 3AA. Each copy should comprise text, references. tables. illustrations and captions in separate sections. The text should have wide margins and consecutively numbered pages and be in double-line spacing throughout.

\section{Texil}

The text should be as concise as possible. Papers should not exceed 5000 words (or word equivalence for figures) or 10 printed pages including figures and tables. Technical notes should not exceed 2000 words (or word equivalence for figures or 4 printed pages in total and discussion contributions should not exceed 500 words.

The text should be in English or French.

Page 1 should give the following information

- date paper written revised

- title of paper (maximum twelve words)

- full names and qualifications of authors

- position affiliation of authors

- contact address. telephone and fax numbers. and e-mail address of principal author

Page 2 should start with an abstract of 100 - 200 words

Capital letters should be used only for proper nouns. Abbreviations for units should conform to the latest edition of BS 350: Part 1. Symbols should conform to symbols and defintions given in the ISSMIFE Lexicon (1981), and be defined where ther first occur in the text and if numerous. listed in a Notation on a separate sheet with special symbols identified and defined

Equations should be numbered and appear on separate lines in the text. The development of mathematical expressions should be presented in appendices with only the relevant equations stated in the body of the paper.

\section{References}

Reforences cited in support of conclusions of the author(s) should be to publications already in print and generally arailable. Where a paper has been accepted for publication elsewhere, but has not yet appeared, the paper submitted to Geotechnique for approval should be accompanied by a copy of the referenced niper.

References should be indicated in the text by authors names with the year of publication in brackets. Details of references should be given in a list (ummumbered) in alphabetical order of atuthors names in the following style.

Books. Author's sumamc. initials. year of publication. title of book. page numbers. place of publication. publisher. e.g.

Wiarne. S. (1993). Principles of enginesing meanization. 2nd edin. Lundon: Thomas Telford.

Periodiculs. Author's surname, initials, year of publication. title of paper, title of periodical. volume, month or part, page numbers. e.g.

Skempton. A. 11. \& Chrimes. M. (1994). Thames Tunnel: site investigation and geotechnical problems. Genechnique 44. No. 2 $191-216$.

Conference prosedings. Author's surname. initials. yeat of publication, title of paper, title of conference proceedings. place of conference. volume. page numbers. e.g.

Bolton. M. D. \& Sun. H. W. (1991). Bridge abutments and spread foundations. Proc loth Ear Conf. Soil lech. Florence 1. $319-322$
Tables

Tables should be supplied on separate pages at the end of the text. They should be referred to in the text and neither duplicate information given in the text nor contain material which would be better presented graphically. Tables should have brief column headings (including units)

\section{Illustrations}

Only those drawings and photographs essential to the understanding of the text should be included. Colour is not used, and so all illustrations must be suitable for reproduction in black and white, Illustrations should be numbered consecutively and referred to in the text. A list of captions for all illustrations should be supplied on a separate page. Illustrations will not normally be returned after publication.

In addition to the printed copies supplied with the text, a set of original illustrations, each marked with the author's name and numbered. should be supplied in the following form.

Photographs should be supplied as glossy prints at least $125 \mathrm{~mm} \times$ $100 \mathrm{~mm}$ in size. They should be sent in stiff packaging and protected from marking and scratching. The correct orientation should be indicated.

Line drawings should be on white or transparent material about At in size, and have thick blick lines. They should be sufficiently clear and simple to enable significant reduction without loss of detail. Dotted screened areas should be aroided. Plans must have a north point and a scale. the axes of graphs must be labsled and numerical values must have dimensions. In addition to the drawings supplied with the text one copy should be supplied without annotations. Line drawings may also be supplied as TIFF ur laps files on disk. and saved at $600 \mathrm{dpi}$.

\section{Supplementary data}

It is the policy of Geolechnigue that. if appropriate and the athor are agreed, back-up information to papers should be made availablo on the Internet. The suggested format is ASCIl or Excel (spreadsheet) files for test data. Excel files for tables and graphs. and ASCII files for text and code segments stch as subroutine from a program. If appropriate. please supply these files on a separate 3.5" floppy disk quoting vour paper number and title. stating clearly what is contained in each file.

Copright

It is the author s responsibility to obtain pemision from the owners of the copright to reproduce material which has heon publiched elsewhere.

\section{Approval and publication procedure}

All papers for Goreshique are sereened through the cieotechnique Advisor: Panet of the ICE. Ground Board.

Papers may fit into one or more of the following categoris: i l analysis. (2) experimental, (3) field work. (4) case history or (5) state-of-the-ant review: In each of these categories there can be aspects or combinations of lat fundamentil properties and behaviour of soil or rock. (b) soil or rock engineering and 6 the practice of geotechnical ingineering. engincoring geology. warthquake engineering or emirommental enginesting.

Papers should be original. demonstrate quality and be of interest to the readership. Analses should be rigornus and scientificalls correct. In experinental papers. technique and apparatus should be clearly described and the data presented in a form that would allow the reader to matic an alternatio interpretation. The problems of providing full information for tield prognammes are recognized. so here the emphasis should be on the darity of presentation and on the usefulness of the findings.

The Geotechnique Advisory Panel apponts an assessor and tiso extemal referees to review the paper for sublability. Based on their advice, the Panel will accept the paper for publication, recommend it be revised prior to accoptance. or reject the paper. If substantial revisions are requested. the resised paper will be treated as a new submission and a full revien undertation. The reteres and ansesson are anonymous. The Panel nominates the published papers for an $\mathrm{ICF}$ award in the following year.

On acceplance of a paper the author will he asked or specily six kevwords for indexing purposes. Before publidant one sed of page proofs will be sem to the principal author onls. Vo new material may be inserted at the time of pront-reading. Tiventy-fice coples of the published paper will be supplied fres of chatroe 